\section{Seed Dressing with Aqueous Allium sativum L. Extracts Enhanced the Tolerance of Maize Plant to Stalk and Ear Rot Disease Caused by Fusarium verticillioides (Sacc.) Nirenberg}

Canadian Journal of Agriculture and Crops

Vol. 5, No. 2, 160-173, 2020

e-ISSN: 2518-6655

$\checkmark$ check for updates $\begin{gathered}\text { check for } \\ \text { updates }\end{gathered}$

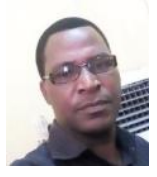

\author{
Ayodele. M. Ajayi
}

Department of Crop, Soil and Pest Management. Federal University of Technology, Akure, Akure, Ondo State, Nigeria.

Email:ajayimy25@yahoo.com Tel:+2348132158030

\title{
ABSTRACT
}

Stalk and ear rot is one of the most common fungal disease of maize. Significant crop failure and yield loss, arising from the disease, are reported annually. Maize grains infected with the pathogen pose serious threat to human and animal health, owing to mycotoxins contamination. The present study evaluated aqueous extracts from Allium sativum in the management of the disease. Four concentrations of the extracts were evaluated against the pathogen in vitro. The most promising concentrations, were applied as seed dressing agents in vivo at 5, 10 and 15-minutes duration for each concentration. Garlic extracts-dressed seeds were then transferred to $F$. verticilliodes infested medium and allowed to germinate and grow for 9 days. Seedlings were transplanted into sterile soils in plastic buckets thereafter. Data collected were subjected to analysis of variance and mean separation. The results obtained showed that peak inhibition of mycelial growth was achieved by $80 \%$ garlic extract concentration $(76.29 \%$ at three days after inoculation). The in vivo study showed that the concentration of garlic extracts as well as the duration of treatment had significant effect on seed germination. Maize seeds dressed with $80 \%$ aqueous garlic extract had the least percentage germination, $43.33 \%$, but recorded the least disease incidence and severity at 2 weeks after transplanting. It also had the best yield, fresh weight of cobs, $303.86 \mathrm{~g}$, and the least percentage of kernel infection with $F$. verticillioides, $15.00 \%$. Garlic extract has potential, as a bio-fungicide, in the management of stalk and ear rot disease of maize.

Keywords: Maize, Stalk and ear rot disease, Fusarium verticillioides Allium sativum, Seed dressing.

DOI: $10.20448 / 803.5 .2 .160 .173$

Citation | Ayodele. M. Ajayi (2020). Seed Dressing with Aqueous Allium sativum L. Extracts Enhanced the Tolerance of Maize Plant to Stalk and Ear Rot Disease Caused by Fusarium verticillioides (Sacc.) Nirenberg. Canadian Journal of Agriculture and Crops, 5(2): 160-173.

Copyright: This work is licensed under a Creative Commons Attribution 3.0 License

Funding: This study received no specific financial support.

Competing Interests: The author declares that there are no conflicts of interests regarding the publication of this paper.

History: Received: 12 June 2020/ Revised: 20 July 2020/ Accepted: 25 August 2020/ Published: 3 September 2020

Publisher: Online Science Publishing 


\section{Highlights of this paper}

- This study evaluated aqueous garlic extract as seed dressing agent in the management of stalk and ear rot disease of maize.

\section{INTRODUCTION}

Maize, (Zea mays L.) has been described as the most important cereal with economic significance in Africa [1]. The crop is of immense importance to man nutritionally and medicinally. Maize grains are important component in the formulation of feed for farm animals and are also essential in the production line of some industries as raw material [2, 3].

Pests and diseases are major limitations to the cultivation of maize worldwide. One of the most common disease is stalk and ear rot (SER) caused by Fusarium verticillioides (Sacc.) Nirenberg [4]. It is a systemic disease favoured by a warm temperature and a dry field condition, especially in the early life of the crop. Infected seed is one major means of dissemination, although residue of the infected maize plants from the previous harvest also play a major role in disease development, serving as a reservoir of inoculum for succeeding planting season. Such residues are also known to be a major source of soil contamination with $F$. verticillioides [5]. Insect vectors, Ostrinia nubilalis (Humber) as an example, spread the disease through the creation of wounds that serves as entry point for the pathogen. The disease cycle usually starts with the infection of the radicle. The pathogen then grows within the stem of standing maize plant and finally get to the ear and kernels, where it causes ear and kernel rot respectively $[6,7]$. In certain cases, infection with the pathogen produce no symptoms and infected plants are said to be asymptomatic. In most cases, however, the leaves of infected plants appear dull-green, while the lower portion of stalk turn yellow. Stalk rot, resulting from the disintegration of the tissues making up the pith, can result in the death and lodging of the infected plants [8] before ear and kernel formation. Infected kernels are characterized by white streaking of the hull, a phenomenon referred to as "starburst". Over time, the entire ear and kernels may rot with conspicuous white mycelium of the infecting pathogen [9]. Poor growth and yield loss, as much as $10-50 \%$, are some of the other symptoms associated with $F$. verticillioides infection of maize [10]. Nutritionally, infected maize grains pose a serious threat to human health and that of farm animals. This is because $F$. verticillioides is known to produce numerous mycotoxins, such as; fumonisins, furasic acid and fusarins [11]. Fumonisins are the most common of these mycotoxins and have been implicated in the development of oesophageal cancer in humans, while aiding cancer-promoting activities in experimental animals like rat [12]. Leukoencephalomalacia disease in horse and pulmonary edema infection in pig are some of the other diseases associated with fumonisins mycotoxins [13].

Current management strategies for stalk and ear rot disease (SERD) have remained largely ineffective, owing to the variability in $F$. verticillioides strains [14]. The use of resistant cultivars seems to be the most promising option, but that again is faced with several challenges, one of which is that not many of such cultivars are available to the rural African farmer [15]. There is a need to look inward and develop easy to use and environment-friendly management options for the disease in rural Africa.

Aqueous extracts from several plants found in Africa are known to possess antifungal properties against several plant pathogenic fungi. Results from the in vitro evaluation of extracts from such plants on their antifungal properties have been reported [16-18]. Reports on the efficacy of garlic extracts in the management of some common plant pathogenic organisms, in vitro, abound in literature [19, 20]. The active ingredient responsible for its antimicrobial properties has been identified to be Allicin. The mode of action of Allicin has been studied and explained elaborately [21-23]. 
There is a need to go beyond the in vitro studies and evaluate these extracts for practical application in plant disease management under field condition. This study was designed as a step in this direction. The first objective was to evaluate $A$. sativum (garlic) extracts for antifungal properties against $F$. verticillioides in vitro, while the second was to evaluate its effectiveness in the management of SERD as a seed dressing agent.

\section{MATERIALS AND METHODS}

\subsection{Collection of the Test Crop}

The yellow maize cultivar evaluated in this study was obtained from The International Institute of Tropical Agriculture (IITA) Ibadan, Nigeria.

\subsection{Preparation of Artificial Growth Medium For Isolation of the Test Organism}

Potato Dextrose Agar (PDA) was the artificial growth medium employed in the isolation of the test organism (F. verticillioides). Powdered PDA was purchased and prepared based on the recommendation of the manufacturer. Sterilization of prepared PDA, all glass and metal wares for the isolation process was done in an autoclave at $121^{\circ} \mathrm{C}$ for 15 minutes. Amendment of PDA with streptomycin antibiotic, $0.2 \mathrm{~g} / 100 \mathrm{ml}$ of agar, after sterilization, was done to inhibit bacterial growth. Pour plating in Petri-dishes, at $15 \mathrm{ml} \mathrm{PDA/Petri-dish,} \mathrm{was} \mathrm{carried} \mathrm{out} \mathrm{when} \mathrm{sterilized}$ and amended PDA cooled to $45^{\circ} \mathrm{c}$. Pour plated PDA were then allowed to gel.

\subsection{Isolation/Identification of the Test Organism And Preparation of Its Pure Culture}

Fusarium verticilliodes, the test organism, was isolated from infected maize seeds, showing the characteristic white streaking of hull, from a farmers field in Akure. Infected seeds were surface sterilized in $70 \%$ alcohol, rinsed in three changes of sterile distilled water and inoculated on prepared PDA in Petri-dishes. Three seeds were inoculated/Petri-dish, equidistant to one another, after drying in sterile absorbent paper Figure 1a. Six of such plates were prepared and incubated at $28^{\circ} \mathrm{C} \pm 2^{\circ} \mathrm{C}$. At day 3 after inoculation, Fusarium spp. was seen growing out from some of the inoculated seeds Figure 1b. Sub-culturing of the isolated Fusarium spp. was done to obtain a pure culture of the organism. Confirmation of the isolated organism as F. verticillioides was based on visual observation of the morphological characteristics in culture plate. Microscopic examination was also done with a CX40 Trinocular Olympus microscope, with reference to the description given by Deepta and Sreenivasa [24]. Pathogenicity test was also carried out for further confirmation.
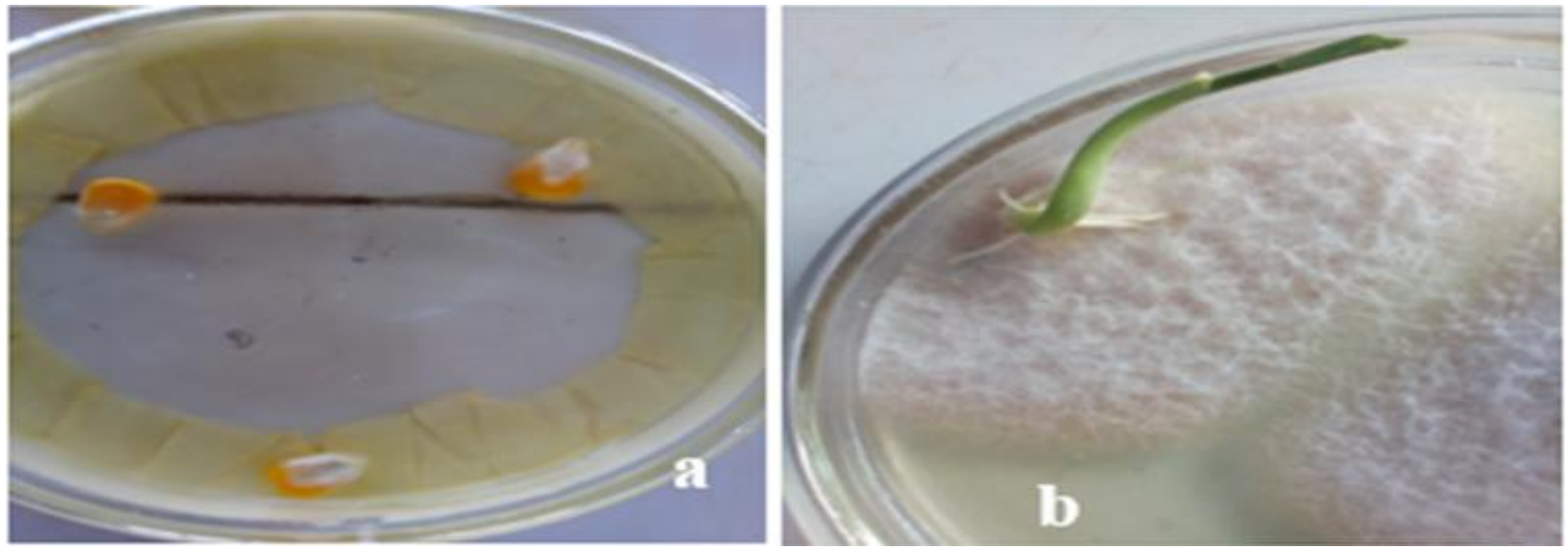

Figure-1 (a). F. verticillioides infected maize seeds inoculated on PDA. (b). Fusarium spp. growing from inoculated maize seeds 


\subsection{Collection and Preparation of A. Sativum Aqueous Extract}

Allium sativum, garlic, was purchased from a fruit and vegetable store at the main market in Akure, Ondo State, Nigeria. Preparation of the aqueous extract was at the pathology laboratory of the Department of Crop, Soil and Pest Management (CSP) the Federal University of Technology, Akure (FUTA). Ondo State, Nigeria. Debris, flaky scale leaves and unhealthy cloves were removed, after which the healthy cloves were washed in sterile distilled water and air-dried. Hot $\left(70^{\circ} \mathrm{c}\right)$ aqueous extract was prepared following the method described by Ajayi [25]. Four different concentrations of $20,40,60$, and $80 \%$ were prepared from the stock solution (100\%) using appropriate dilutions with sterile distilled water. Ten (10) $\mathrm{ml}$ of each concentration was prepared in sterile specimen bottles.

\subsection{Evaluation of A. Satioum for Antifungal Properties Against F. Verticillioides}

Potato dextrose agar (PDA) growth medium was prepared as described previously but with a little modification. This was to make up for the expected decrease in the PDA content of the growth medium after the addition of garlic extracts. Instead of the recommended $3.9 \mathrm{~g}$ of powdered PDA in $100 \mathrm{ml}$ of distilled water by the manufacturer, $4.4 \mathrm{~g}$ was used. Pour plating was done at the rate of $13 \mathrm{ml}$ of PDA/Petri-dish when sterilized PDA was $50^{\circ} \mathrm{c}$. Two $(2) \mathrm{ml}$ of garlic extracts was added to the pour plated agar in each Petri-dish, using a sterile syringe, followed by gentle swerving to ensure proper mixing of the PDA and garlic extracts. The same procedure was adopted in the preparation of the standard check and the control. The standard check was a synthetic fungicide “Dress Force 42 WS" (Imidacloprid 20\%, Metalaxyl-M 20\% and Tebuconazole 2\%), while the control was sterile distilled water. Each Petri-dish, therefore, contained $15 \mathrm{ml}$ of PDA/Garlic extracts. The standard check had PDA/Dress Force, while the control had PDA/Distilled water complex. The garlic extracts were at four different concentrations, 20, 40, 60 and 80\%. Powdered Dress Force was diluted to a concentration of $12.5 \mathrm{mg} / \mathrm{ml}$, based on an estimation of the recommendation for use by the manufacturer. The width of each Petri-dish was $8.50 \mathrm{~cm}$. A 5 mm agar disc, from a 5-day old culture of $F$. verticillioides was inoculated at the center of the PDA complex in each Petri-dish. Each treatment was replicated four times, such that a total of 24 experimental units were evaluated in all. The treatments were laid out in a completely randomized design. Incubation was done at $28^{\circ} \mathrm{C} \pm 2^{\circ} \mathrm{c}$, while mycelial growth was measured at three-day interval.

\subsection{Preparation of Garlic Extract/Starch Slurry and Seed Dressing of Maize}

Twenty (20) \% aqueous garlic extracts was the least effective form the in vitro study. It was consequently excluded in the preparation of garlic extract/starch slurry for seed dressing. Three (3) concentrations, 40, 60 and $80 \%$ of the extracts were prepared as described previously. Dry granules of commercially produced instant coldwater starch, to mimic adjuvant and adhesive agent in conventional fungicides, was added to each concentration of garlic extracts at the rate of $25 \mathrm{mg} / \mathrm{ml}$, after which stirring was done to allow for complete dissolution of the granules and the formation of garlic extract/starch slurry. Twenty (20) $\mathrm{ml}$ of the slurry was obtained from each concentration and 60 healthy maize seed were placed in each. The seeds were allowed to remain in the respective garlic slurry concentrations for 5,10 and 15 minutes. A separate garlic slurry concentration was prepared for each treatment duration. The standard check, “Dress Force” was prepared as a slurry, based on manufacturer's recommendations. Starch granules was not added. The control had $20 \mathrm{ml}$ of distilled water/starch slurry.

\subsection{Preparation of F. Verticillioides Infested Medium and Sowing of Dressed Maize Seeds}

The sowing medium was 6 layers of sterile absorbent paper in each Petri-dish. Each medium was moistened with $30 \mathrm{ml}$ of spore suspension, at $10^{6}$ spores $/ \mathrm{ml}$, of $F$. verticillioides. The spores were harvested from 6-day old 
cultures of the pathogen, while the required spore concentration was obtained with the aid of a haemocytometer slide. Dressed maize seeds for all treatments (garlic extract concentrations at three-time interval, the standard check and control) were placed in each Petri-dish at the rate of 20 seeds/Petri-dish. Fifteen (15) treatments were evaluated and each was replicated thrice, making a total of 45 experimental units. The treatments were laid out on the side bench in the pest laboratory of CSP Department. Wetting was done as required with equal volume of sterile distilled water for all treatments. Sowed seeds were examined daily and seedlings were allowed to grow in the $F$. verticillioides infested medium for 9 days.

\subsection{Collection/Sterilization of Soil and Transplanting of Seedlings From F. Verticillioides Infested Medium}

Sandy loam soil was collected from FUTA Teaching and Research Farm and was sterilized using the steam heat method as described by Bollen [26]. The sterilized soil was transferred into 5-liter capacity plastic buckets at the rate of $4 \mathrm{~kg}$ of soil/bucket. Each bucket had 6 small holes, $3 \mathrm{~mm}$ diameter each, at the base. Two 9-day old seedlings from 5 minutes treatment, being the best in terms of germination percentages, in each garlic extracts complexes were selected randomly and were transferred to sterile soil in plastic buckets. Each bucket had a corresponding treatment label with the $F$. verticillioides infested medium (FvIM) from where the maize seedlings were transplanted. The experiment was laid out in a completely randomized design in the screen house of CSP Department. Irrigation was done as required with sterile distilled water, while the fertilizer applied was NPK 15:15:15 at the recommended rate of $200 \mathrm{~kg} / \mathrm{ha} .(3.8 \mathrm{~g} / \mathrm{stand})$.

\subsection{Data Collection and Statistical Analysis}

Data were collected on the following parameters.

\subsubsection{Mycelial Growth of F. Verticillioides.}

The measurement of mycelial growth was done at 3-day interval and was terminated on the $9^{\text {th }}$ day when complete coverage of the growth medium in the control plate with the mycelium of $F$. verticillioides was achieved. The measurement of mycelial growth was with a meter rule. The values obtained for the treatments were converted to percentage mycelial growth inhibition using Equation 1.

$$
i m=\frac{m g c-m g t}{m g c} \times \frac{100}{1}
$$

Where;

im $=$ inhibition of mycelial growth.

$m g c=$ mycelial growth in control plate

$m g t=$ mycelial growth in treated plate.

\subsubsection{Germination of Maize Seeds in F. Verticillioides Infested Medium (\%)}

Maize seeds sown in FvIM in Petri-dishes were examined daily. The number of germinated seeds, those with emerged radicle, were counted. The values obtained were converted to percentage seed germination with Equation 2 .

$$
p s g=\frac{n g s}{n s s} x \frac{100}{1}
$$

Where;

$p s g=$ percentage seed germination . 
$n g s=$ number of germinated seeds.

$n s s=$ number of seeds sown.

2.9.3. Shoot Length

On the $9^{\text {th }}$ day, after sowing in FvIM, maize seedlings were carefully removed, to prevent the roots from breaking off. The shoot of each seedling was measured one after the other with a meter rule. The mean of the values obtained in each replicate was calculated and recorded.

\subsubsection{Root Length}

After 9 days of growth in the pathogen infested medium (PIM), the length of the primary root of each seedling was measured. The mean values obtained for each experimental unit was also recorded.

\subsubsection{The Number of Roots Produced by Seedlings}

At the end of the 9-day growth period in FvIM, the number of roots produced by each seedling in all the treatments was counted. The mean value was calculated and recorded.

\subsubsection{Incidence of Stalk and Ear Rot Disease (\%)}

The transplanted maize in plastic buckets were examined weekly for expression of symptoms of SERD from the $2^{\text {nd }}$ week after transplanting (WAT). The incidence of the disease was determined and recorded in percentage for each treatment with Equation 3.

$$
d i=\frac{n d l}{t n l} \times \frac{100}{1}
$$

Where;

$d i=$ disease incidence.

$n d i=$ number of diseased leaves showing symptoms of SERD.

$t n l=$ total number of leaves on the plant.

\subsubsection{Severity of Stalk and Ear Rot Disease}

Symptoms indicative of SER infection on maize stem was observed visually during the growing period of the plant and at harvest. The modified severity rating scale cited by Afolabi, et al. [15] was adopted. It consisted of a 0 -5 rating where;

$\mathrm{O}=$ No symptom of infection.

$1=1-25 \%$ of the leaf shows a symptom of infection $/ 1-2 \mathrm{~cm}$ diameter lesion of rot on the stem.

$2=26-50 \%$ of the leaf shows a symptom of infection $/ 2.1-3 \mathrm{~cm}$ diameter lesion of rot on the stem.

$3=51-75 \%$ of the leaf shows a symptom of infection $/ 3.1-4 \mathrm{~cm}$ diameter lesion of rot on the stem.

$4=76-100 \%$ of the leaf shows a symptom of infection/ $4.1-5 \mathrm{~cm}$ diameter lesion of rot on the stem.

$5=$ Death and lodging of the maize plant.

\subsubsection{Cob Yield of Maize Plants (g)}

Maize cobs were allowed to dry before harvest. Weighing of cobs was done immediately after harvest and the value obtained for each treatment was recorded as cob fresh weight. 


\subsubsection{Infection of Kernels with F. Verticillioides}

Harvested cobs were shelled and sun-dried for one week. Thereafter, 20 seeds were selected randomly from each treatment. The selected seeds were surface sterilized in $70 \%$ alcohol, rinsed in several changes of sterile distilled water and pat dried with sterile absorbent paper. Sterilized maize seeds were inoculated on PDA medium in Petri-dishes at the rate of 5 seeds/Petri-dish. The number of $F$. verticillioides infected seeds were counted and expressed in percentage infection of kernels with Equation 4.

$$
\text { pis }=\frac{\text { tis }}{\text { tin }} \times \frac{100}{1}
$$

Where;

pis $=$ percentage infection of seed.

tis $=$ number of infected seeds.

tin $=$ number of inoculated seeds.

\subsection{Treatments Evaluated in the in Vivo Study}

The treatments were evaluated in the in vivo study were

i. Garlic extracts at $40 \%$ concentration $=\mathrm{G} 40$ at 5,10 - and 15 -minutes seed treatment duration.

ii. Garlic extracts at $60 \%$ concentration $=\mathrm{G} 60$ at 5,10 - and 15 -minutes seed treatment duration.

iii. Garlic extracts at $80 \%$ concentration $=\mathrm{G} 80$ at 5, 10- and 15-minutes seed treatment duration.

iv. Synthetic fungicide as standard check $=\mathrm{SDC}$ at 5,10 - and 15 -minutes seed treatment duration.

v. Control $=\mathrm{CNT}$ at 5,10 - and 15 -minutes seed treatment duration.

All data collected were subjected to analysis of variance (ANOVA) using Minitab software, Version 17. Mean separation was achieved with Tukey's test.

\section{RESULTS}

\subsection{Effect of Aqueous A. Satioum Extract on the Mycelial Growth of F. Verticillioides}

The inhibition of mycelial growth (IMG) of $F$. verticillioides, by aqueous garlic extracts, increased with the increasing concentration of the extracts. Significant differences were observed among treatments, especially at the $3^{\text {rd }}$ and $6^{\text {th }}$ day after inoculation Figure $2 \mathrm{a}$, Table 1 . A decreased efficacy in the inhibitory activity of the extracts was however observed with the increasing number of days after inoculation Table 1. On the $3^{\text {rd }}$ day after inoculation, $80 \%$ garlic concentration inhibited the mycelial growth of $F$. verticillioides by $76.29 \%$. This was the highest value among the extract concentrations. Next was $60 \%$ garlic extract concentration with $51.33 \%$ IMG, while $40 \%$ concentration had $40.95 \%$ IMG. The least value of mycelial growth inhibition, $20.74 \%$, was exhibited by $20 \%$ gallic extract concentration Table 1. The same pattern of IMG was observed on the $6^{\text {th }}$ and $9^{\text {th }}$ day after inoculation. It must be pointed out however that 40 and $60 \%$ garlic extract concentrations were not significantly different in their IMG of $F$. verticillioides on the $9^{\text {th }}$ day after inoculation Table 1.

\subsection{Effect of Seed Dressing of Maize with Garlic Extracts on Germination (\%)}

A surprising trend of decreasing germination percentage with an increasing concentration of garlic extracts was observed Table 2. On the $2^{\text {nd }}$ day after sowing, the control (CNT) had the highest percentage germination, $58.33 \%$, among seeds that were treated for 5 minutes in garlic extracts slurry (GES). This value was however not statistically ( $\mathrm{p} \leq 0.05$ ) different from garlic extract slurry at $40 \%$ concentration $(\mathrm{G} 40)$ and the standard check (SDC). 
In seeds treated for 10 minutes in GES, SDC had the highest germination percentage, 60.00\%. G40, CNT and SDC were statistically similar.

Table-1. Inhibition of mycelial growth of $F$. verticillioides by $A$. sativum extract (\%).

\begin{tabular}{|c|c|c|c|}
\hline \multirow[t]{2}{*}{ Treatments } & \multicolumn{3}{|c|}{ Inhibition of mycelial growth/ days after inoculation } \\
\hline & 3 & 6 & 9 \\
\hline G20 & $20.74 \mathrm{e}$ & $10.18 \mathrm{e}$ & $8.68 \mathrm{~d}$ \\
\hline $\mathrm{G} 40$ & $40.95 \mathrm{~d}$ & $36.34 \mathrm{~d}$ & $32.22 \mathrm{c}$ \\
\hline G60 & $51.33 \mathrm{c}$ & $42.87 \mathrm{c}$ & $33.72 \mathrm{c}$ \\
\hline G80 & $76.29 \mathrm{~b}$ & $65.64 b$ & $63.04 \mathrm{~b}$ \\
\hline $\mathrm{SDC}$ & 83.09a & $71.80 \mathrm{a}$ & $68.87 a$ \\
\hline
\end{tabular}

$=$ Garlic extract at $80 \%$ concentration, $\mathrm{SDC}=$ Standard check

A similar trend was observed among seeds treated for 15 minutes, but CNT had the highest germination percentage, $60.00 \%$. On a general note, maize seeds treated with $80 \%$ GES had significantly lowest germination percentages on the $2^{\text {nd }}$ day after sowing, $18.33 \%, 18.33 \%$ and $15.00 \%$ at 5,10 - and 15 -minutes treatment time Table 2. On the $3^{\text {rd }}$ day after sowing in PIM, germination percentages were higher in all treatments than the previous day. Among seeds treated for 5 minutes before sowing in PIM, SDC had the highest germination percentage of $75.00 \%$, while G80 had the lowest, 40.00\%, The two values were significantly ( $\mathrm{p} \leq 0.05$ ) different. SDC, CNT and G40 were not statistically similar Table 2. When seeds were treated for 10 minutes GES before sowing in the PIM, the highest germination percentage of $76.00 \%$ was obtained from SDC, while the least, $36.66 \%$ was obtained from G80. Germination percentage in G80 further declined to 26.66\% when seeds were treated in slurry for 15 minutes before sowing. SDC had the highest germination percentage at this period, 73.33\%, Table 2. Peak germination was attained on the $4^{\text {th }}$ day after sowing.

Table-2. Effect of seed treatment with different concentrations of garlic extracts on the germination of maize seeds (\%).

\begin{tabular}{|c|c|c|c|}
\hline \multirow[t]{2}{*}{ Treatments } & \multicolumn{3}{|c|}{ Germination (\%)/Duration of treatment in garlic extract (Minutes) } \\
\hline & $\mathbf{5}$ & 10 & 15 \\
\hline & \multicolumn{3}{|c|}{2 Days after sowing in $F$. verticillioides infested medium } \\
\hline $\mathrm{G} 40$ & $56.66 \mathrm{a}$ & $53.33 \mathrm{a}$ & $55.00 \mathrm{a}$ \\
\hline G60 & $40.00 b$ & $31.66 \mathrm{~b}$ & $40.00 b$ \\
\hline G80 & $18.33 \mathrm{c}$ & $18.33 \mathrm{c}$ & $15.00 \mathrm{c}$ \\
\hline CNT & $58.33 \mathrm{a}$ & $56.66 \mathrm{a}$ & $60.00 a$ \\
\hline \multirow[t]{2}{*}{ SDC } & $56.66 \mathrm{a}$ & $60.00 \mathrm{a}$ & $58.33 \mathrm{a}$ \\
\hline & \multicolumn{3}{|c|}{3 Days after sowing in $F$. verticillioides infested medium } \\
\hline $\mathrm{G} 40$ & $70.00 \mathrm{ab}$ & $71.66 \mathrm{a}$ & $66.66 \mathrm{ab}$ \\
\hline G60 & $63.33 \mathrm{~b}$ & $58.33 \mathrm{~b}$ & $58.33 \mathrm{~b}$ \\
\hline G80 & $40.00 \mathrm{c}$ & $36.66 \mathrm{c}$ & $26.66 \mathrm{e}$ \\
\hline CNT & $71.66 \mathrm{ab}$ & $70.00 \mathrm{a}$ & $70.00 \mathrm{ab}$ \\
\hline \multirow[t]{2}{*}{ SDC } & $75.00 \mathrm{a}$ & $76.00 \mathrm{a}$ & $73.33 \mathrm{a}$ \\
\hline & \multicolumn{3}{|c|}{4 Days after sowing in $F$. verticillioides infested medium } \\
\hline $\mathrm{G} 40$ & $73.33 \mathrm{a}$ & $75.00 \mathrm{a}$ & $68.33 \mathrm{~b}$ \\
\hline G60 & $65.00 b$ & $61.66 \mathrm{~b}$ & $61.66 \mathrm{c}$ \\
\hline G80 & $43.33 \mathrm{c}$ & $38.33 \mathrm{c}$ & $26.66 \mathrm{~d}$ \\
\hline CNT & $76.66 \mathrm{a}$ & $75.00 \mathrm{a}$ & $73.33 \mathrm{ab}$ \\
\hline $\mathrm{SDC}$ & $75.00 \mathrm{a}$ & $78.33 \mathrm{a}$ & $76.66 \mathrm{a}$ \\
\hline
\end{tabular}

Note: Means in the same column followed by the same alphabets for each day after sowing are not significantly different $(\mathrm{p} \leq 0.05)$ according to Tukey's test. Key. $\mathrm{G} 40=$ Garlic extract at $40 \%$ concentration, G60 = Garlic extract at $60 \%$ concertation, G80 = Garlic extract at $80 \%$ concentration, $\mathrm{CNT}=\mathrm{Control}$, SDC= Standard check.

Among seeds treated with slurry for 5 and 10 minutes before sowing in PIM G40, CNT and SDC both produced germination percentages above $70.00 \%$. The values of germination percentages produced by the three 
treatments were all similar statistically. G80 produced significantly lowest germination percentages of $43.33 \%$, $38.33 \%$ and $26.66 \%$ when seeds were treated in garlic extracts for 5, 10 and 15 minutes respectively Table 2. Finally, the duration of treatment before sowing had no noticeable effect on seeds from SDC, and CNT as no definite germination pattern was observed across the 3-time treatment durations for both treatments.

\subsection{Effect of Seed Dressing of Maize With Garlic Extracts on the Shoot Length of Seedlings (Cm)}

The least value of shoot length, $3.77 \mathrm{~cm}$, was obtained from maize seeds treated with $80 \%$ garlic extract concentration for 15 minutes (T9) before transferring to the PIM Figure 2b, Table 3. The highest value, $6.69 \mathrm{~cm}$ was obtained from the standard check (T11) at 5 minutes treatment before transferring to the PIM Table 2. An interesting observation, however, was that shoot length was statistically very similar among most of the treatments Table 3.
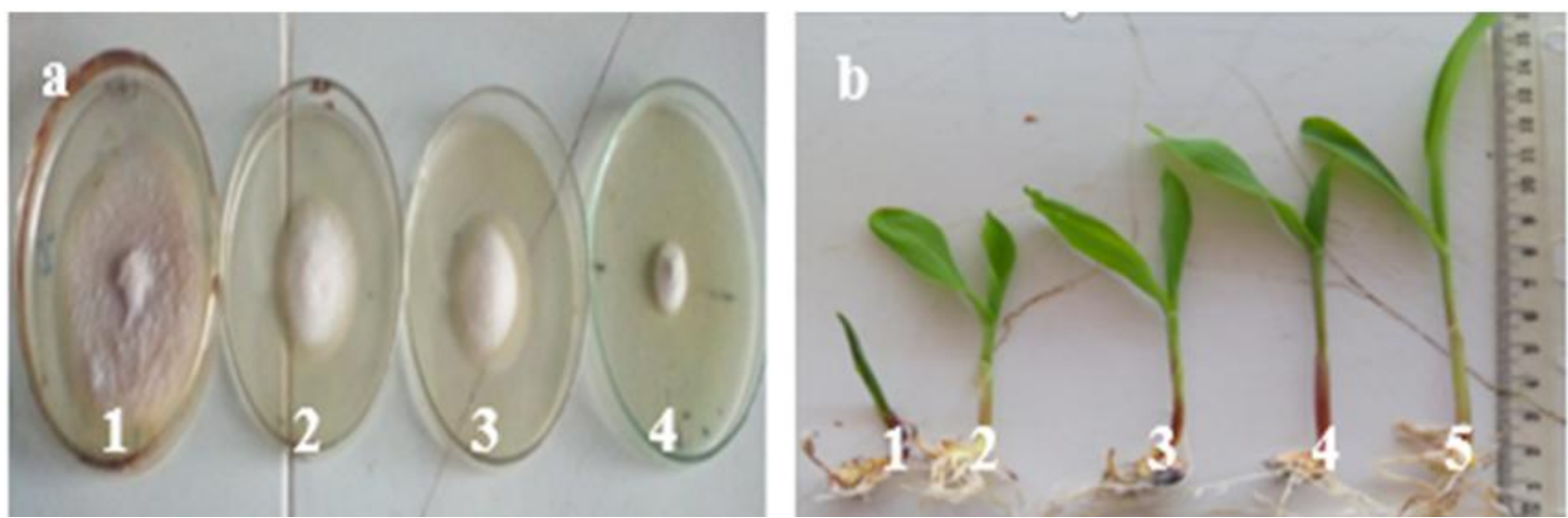

Figure-2. (a). F. verticillioides in PDA/Garlic extract medium at 9 days after inoculation $1=20 \%, 2=40 \%, 3=60 \%, 4=80 \%$. (b). Seedlings from maize seeds dressed with different concentrations of garlic extract and grown in F. verticillioides infested medium for 9 days. $1=80 \%, 2=60 \%$, $3=40 \%, 4=\mathrm{SDC}, 5=\mathrm{CNT}$.

3.4. Effect of Seed Dressing of Maize with Garlic Extracts on the Root Length of Seedlings (cm)

In a similar fashion to the result obtained for shoot length, the shortest root length from seedlings was also obtained from maize seeds treated with $80 \%$ garlic extract for 15 -minutes, T9. Root length was $2.26 \mathrm{~cm}$. The highest root length value of $7.06 \mathrm{~cm}$ was obtained from the standard check, T11, Table 3. Root length was, however, very similar statistically among most of the treatments Table 3.

Table-3. Effect of treatment with different concentrations of garlic slurry on the shoot length, root length and the number of roots of maize seedlings.

\begin{tabular}{|c|c|c|c|}
\hline \multirow{2}{*}{\multicolumn{2}{|c|}{$\begin{array}{c}\text { Treatments } \\
\text { Shoot length }(\mathrm{cm})\end{array}$}} & \multicolumn{2}{|c|}{ Parameters evaluated } \\
\hline & & Root length (cm) & \\
\hline $\mathrm{T} 1$ & $4.91 \mathrm{bc}$ & $5.78 \mathrm{ab}$ & $7.34 \mathrm{abc}$ \\
\hline $\mathrm{T} 2$ & $5.47 \mathrm{ab}$ & $5.89 \mathrm{ab}$ & $9.14 a$ \\
\hline Т3 & $5.90 a b$ & $6.48 \mathrm{a}$ & $7.61 \mathrm{abc}$ \\
\hline $\mathrm{T} 4$ & $5.70 a b$ & $6.46 \mathrm{a}$ & $5.91 \mathrm{~cd}$ \\
\hline T5 & $4.91 \mathrm{bc}$ & $4.81 \mathrm{ab}$ & $5.74 \mathrm{cde}$ \\
\hline Т6 & $4.80 \mathrm{bc}$ & $4.86 a b$ & $6.55 \mathrm{bcd}$ \\
\hline $\mathrm{T} 7$ & $4.87 \mathrm{bc}$ & $5.84 a b$ & 4.99de \\
\hline $\mathrm{T} 8$ & $4.53 \mathrm{bc}$ & $3.85 \mathrm{bc}$ & $5.77 \mathrm{~cd}$ \\
\hline Т9 & $3.77 \mathrm{c}$ & $2.26 \mathrm{c}$ & $3.66 \mathrm{e}$ \\
\hline $\mathrm{T} 10$ & $6.69 \mathrm{a}$ & $6.89 \mathrm{a}$ & $8.61 \mathrm{ab}$ \\
\hline $\mathrm{T} 11$ & $6.81 \mathrm{a}$ & $7.06 \mathrm{a}$ & $8.91 \mathrm{a}$ \\
\hline
\end{tabular}

Note: Means in the same column followed by the same alphabets are not significantly different $(\mathrm{p} \leq 0.05)$ according to Tukey's test. 
Key; $\mathrm{T} 1=40 \%$ garlic slurry concentration, 5 minutes duration of maize seeds treatment, $\mathrm{T} 2=40 \%$ garlic slurry concentration, 10 minutes duration of maize seeds treatment, T3=40\% garlic slurry concentration, 15 minutes duration of maize seeds treatment, $\mathrm{T} 4=60 \%$ garlic slurry concentration, 5 minutes duration of maize seeds treatment, $\mathrm{T} 5=60 \%$ garlic slurry concentration, 10 minutes duration of maize seeds treatment, T $6=60 \%$ garlic slurry concentration, 15 minutes duration of maize seeds treatment, T $7=80 \%$ garlic slurry concentration, 5 minutes duration of maize seeds treatment, T8 $=80 \%$ garlic slurry concentration, 10 minutes duration of maize seeds treatment, $\mathrm{T} 9=80 \%$ garlic slurry concentration, 15 minutes duration of maize seeds treatment, $\mathrm{T} 10=\mathrm{Sterile}$ water slurry, 5 minutes duration of maize seeds treatment (Control), T11= Synthetic chemical slurry, 5 minutes duration of maize seeds treatment (Standard check).

\subsection{Effect of Seed Dressing of Maize with Garlic Extracts on the Number of Roots Produced by Seedlings}

The highest number of roots, 9.14, was produced by maize seeds treated with $40 \%$ garlic extract concentration for 10 minutes before sowing in PIM (T4) while the least, 3.66, was produced by seeds treated with $80 \%$ garlic extract concentration for 15 minutes before sowing in FvIM, T9. Most of the treatments were not significantly different with regard to root production Table 3.

\subsection{Effect of Seed Dressing of Maize With Garlic Extract on the Incidence of Stalk and Ear Rot Disease (\%)}

On the $2^{\text {nd }}$ WAT, $54.66 \%$ disease incidence was recorded from G40. This was significantly higher than all other treatments. G80 and SDC both had $0.00 \%$ disease incidence and were significantly the lowest Table 4 . By the $4^{\text {th }}$ WAT, G40 had $86.83 \%$ disease incidence, while CNT had $89.33 \%$. The two values were not significantly (p $\leq 0.05)$ different, but differed from 17.23\% obtained from G80. G80 had significantly lowest disease incidence at this period. On the $6^{\text {th }}$ WAT, disease incidence declined in G40, G60 and CNT, while G80 and SDC increased moderately. Two treatments, G60 and G80 were statistically similar at this period and were significantly lower than the remaining three treatments Table 4.

\subsection{Effect of Seed Dressing of Maize with Garlic Extract on the Severity of Stalk and Ear Rot Disease}

The result obtained on disease severity showed that on the $2^{\text {nd }}$ WAT, G40 had the highest value, 1.50. This was however statistically similar to 1.00 and 1.33 obtained from G60 and CNT respectively. By the $4^{\text {th }}$ WAT, a different picture emerged. The severity of SERD in CNT had increased to 3.66. This was the highest value. It differed significantly from all other treatments. G40 had the second highest disease severity value of 2.33 Table 4. G60, G80 and SDC had 1.66, 1.00 and 1.00 respectively. The three values were not significantly different. Result for disease severity on the $6^{\text {th }}$ WAT showed that G60, G80 and SDC all had 1.0, while G40 had 1.66. The four values were not significantly different. Significantly highest value of 3.90 was obtained from CNT Table 4.

Table-4. Effect of seed dressing of maize with garlic extracts on the incidence and severity of stalk and ear rot disease.

\begin{tabular}{|c|c|c|c|c|c|c|}
\hline \multirow[t]{2}{*}{ Treatments } & \multicolumn{3}{|c|}{ Disease incidence (\%)/WAT } & \multicolumn{3}{|c|}{ Disease severity/WAT } \\
\hline & 2 & 4 & 6 & 2 & 4 & 6 \\
\hline G40 & $54.66 \mathrm{a}$ & $86.83 \mathrm{a}$ & $32.77 \mathrm{a}$ & $1.50 \mathrm{a}$ & $2.33 \mathrm{~b}$ & $1.66 \mathrm{ab}$ \\
\hline G60 & $21.66 \mathrm{c}$ & $27.23 \mathrm{~b}$ & $23.46 \mathrm{~b}$ & $1.00 \mathrm{a}$ & $1.66 \mathrm{bc}$ & $1.00 \mathrm{~b}$ \\
\hline G80 & o.ood & $17.23 \mathrm{c}$ & $21.36 \mathrm{~b}$ & $0.00 b$ & $1.00 \mathrm{c}$ & $1.00 \mathrm{~b}$ \\
\hline CNT & $45.00 \mathrm{~b}$ & $89.33 \mathrm{a}$ & $39.77 \mathrm{a}$ & $1.33 \mathrm{a}$ & $3.66 \mathrm{a}$ & $3.90 \mathrm{a}$ \\
\hline $\mathrm{SDC}$ & o.ood & $23.61 \mathrm{~b}$ & $31.94 \mathrm{a}$ & $0.00 b$ & $1.00 \mathrm{c}$ & $1.00 \mathrm{~b}$ \\
\hline
\end{tabular}


Key: WAT $=$ Weeks after transplanting, $\mathrm{G} 40=$ Garlic extract at $40 \%$ concentration, G60 $=$ Garlic extract at $60 \%$ concertation, G80 = Garlic extract at $80 \%$ concentration, $\mathrm{CNT}=$ Control, $\mathrm{SDC}=$ Standard check.

\subsection{Effect of Seed Dressing of Maize with Garlic Extracts on Cob Fresh Weight (G)}

Maize plants from seeds treated with $80 \%$ garlic extract, G80, produced the biggest cobs with significantly $(\mathrm{p} \leq$ 0.05 ) heaviest weight of $303.86 \mathrm{~g}$. Figure 3. Cobs from G60 and SDC weighed 270.71 and 270.54 g respectively. The two values were statistically similar. The least weight of cobs, $110.44 \mathrm{~g}$ was obtained from CNT Figure 3.

a $\mathrm{CFW}(\mathrm{g}) \quad \mathrm{KI}(\%)$
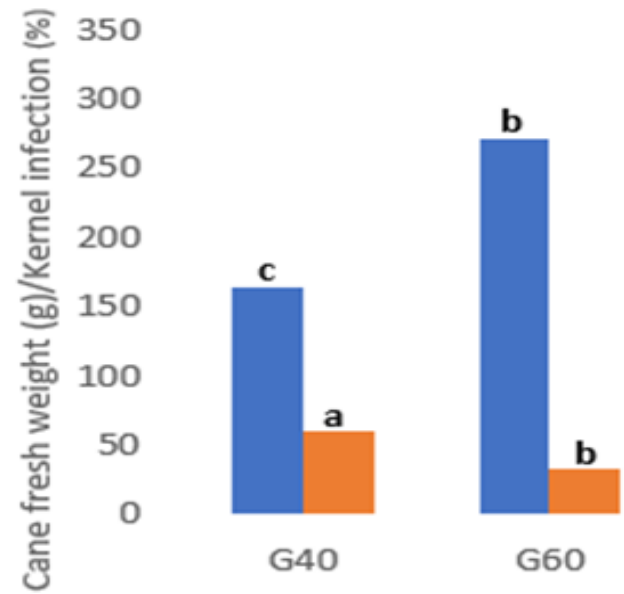

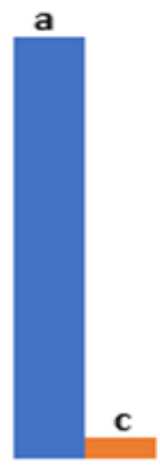

G80

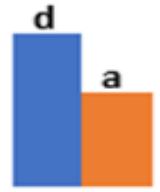

CNT

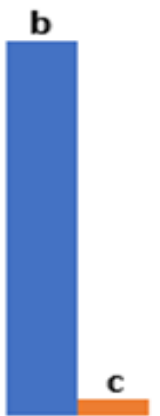

SDC

Treatments

Figure-3. Effect of seed treatment with garlic extracts on cob fresh weight and kernel infection of maize Key: $\mathrm{CFW}=\mathrm{Cob}$ fresh weight, $\mathrm{KI}=$ Kernel infection, G40 $=$ Garlic extract at $40 \%$ concentration, G60 $=$ Garlic extract at $60 \%$ concertation, $\mathrm{G} 80=$ Garlic extract at $80 \%$ concentration, $\mathrm{CNT}=$ Control, $\mathrm{SDC}=$ Standard check.

\subsection{Effect of Seed Dressing of Maize With Garlic Extracts on Kernel Infection with F. Verticillioides}

The lowest percentage of kernel infection with $F$. verticillioides, $15.00 \%$, was obtained from G80 Figure 3. This value was however statistically similar to $11.66 \%$ obtained from SDC. The highest percentage infection, $68.33 \%$ was obtained from CNT. It was statistically not different from $60.00 \%$ obtained from G40 Figure 3.

\section{DISCUSSION}

Result from the in vitro studies showed that garlic extract possesses antifungal properties against $F$. verticillioides. The observed trend was an increasing percentage inhibition of mycelial growth of the pathogen as the concentrations of garlic extracts increased. The inhibitory effect of the extract however declined with increasing number of days after inoculation of the pathogen across all the concentrations evaluated. Similar findings on the antifungal properties of garlic extract against other common fungal pathogens of crops have been reported by scholars [20, 25]. The decrease in fungistatic property with increasing days after inoculation may be due to the degradation of the bioactive components in the garlic extract.

The germination of treated maize seeds in FVIM started from the second day after sowing and increased progressively until the fourth day when no new germinations were recorded. A surprising observation was that overall percentage germination decreased with increasing concentration of garlic extracts, such that the lowest overall percentage germination was obtained from maize seeds treated with $80 \%$ garlic extract concentration. This was a direct opposite of the impact of garlic extract on $F$. verticillioides in the in vitro study and was unexpected. Report from literature however, confirmed the observed result of decreasing germination percentage of maize seeds with increasing concentration of garlic extracts. Cheng, et al. [27] reported that certain allelochemicals are present 
in garlic. They pointed out that such chemicals exert allelopathic effect on seed germination, root growth and seedling development when garlic extracts are used as seed treatment agent. The most prominent of these chemicals was reported to be Dailly Disulfide (DDS). At low concentrations of garlic extracts, the impact of DDS is minimal or non-existent. Consequently, rapid and high overall percentage germination, root development and good seedling vigour are enhanced. This observation was reported earlier by Perello, et al. [23]. At high concentrations however, DDS concentration increases, so also does it allelopathic effect, bringing about poor seed germination, poor root development and seedlings with less vigour. This explanation must have accounted for the poor overall percentage germination in maize seeds treated with $80 \%$ garlic extract concentration, as well as the few number and poorly developed roots exhibited by them within the PIM. It also explains the decreased percentage germination with increased length of time maize seeds were allowed to remain in garlic extracts concentrations before sowing. Ali, et al. [28] reported a similar finding on the effect of garlic extracts on the germination of Solanum melongena.

Disease incidence and severity were high in maize plants whose seeds were treated with $40 \%$ garlic extract and the control. Seeds from the two treatments germinated quickly and grew rapidly within the $F$. verticillioides infested medium, but succumbed to infection by the pathogen easily after transplanting. This may be due to the fact that the low concentration/non-availability of garlic extract allowed unhindered growth, infection and colonization of the root system by $F$. verticillioides. Pathogenesis continued unhindered after transplanting, resulting in the manifestations of symptoms of SERD.

Few weeks after transplanting, growth activities in maize plants whose seeds were subjected to $80 \%$ garlic extract treatment suddenly picked up. By the $8^{\text {th }}$ weeks after transplanting, the treatment produced plants with the best growth parameters. The most reasonable explanation is that few numbers of roots produced, due to the effect of DDS, brought about less contact with $F$. verticillioides while growing within the PIM. The high concentration of garlic extracts around the seeds may have equally inhibited the growth of $F$. verticillioides. These facts may have prevented infection and the onset of pathogenesis. It is also possible that a defense response may have been initiated in the maize seedlings as a result of some priming effects that may have been conferred by garlic extracts at $80 \%$ concentration. Hayat, et al. [29] had reported a similar finding. The fact that disease incidence and severity were very low in the treatments may be a confirmation of this view.

The control had the least fresh weight of cob and an equally high percentage of kernel infection with $F$. verticillioides. This is understandable, considering the high incidence and severity of SERD. Poor yield, in terms of quality and quantity is often associated with diseased crops, especially in susceptible varieties [10, 30]. The high percentage of infected kernels, especially in $40 \%$ garlic slurry and the control is a confirmation of report from literature on the seeds as the most important source of transmission of $F$. verticilliodes [6].

\section{CONCLUSION AND RECOMMENDATION}

Results from this study showed that garlic extracts possess antifungal properties against $F$. verticillioides. It may also have conferred protection on maize plant against SERD at $80 \%$ concentration, leading to improved growth performance and yield. Further work needs to be done on the DDS component of the extract before outright recommendation of its use in the management of SERD of maize. There is also a need for the evaluation of garlic extracts as foliar spray against SERD of maize.

\section{REFERENCES}


[1] A. B. Olaniyan, "Maize: Panacea for hunger in Nigeria," African Journal of Plant Science, vol. 9, pp. 155-174, 2015. Available at: https://doi.org/10.5897/ajps2014.1203.

[2] A. A. Abdulrahaman and O. M. Kolawole, "Traditional preparation and the use of maize in Nigeria," Ethnobotanical Leaflets, vol. 10, pp. 219-227, 2006.

[3] D. Kumar and N. A. Jhariya, "Nutritional, medicinal and economic importance of corn; A mini review," Research Journal of Pharmaceutical Science, vol. 2, pp. 7-8, 2013.

[4] W. Marasas, "Discovery and occurrence of the fumonisins: A historical perspective," Environmental Health Perspectives, vol. 109, pp. 239-243, 2001. Available at: https://doi.org/10.2307/3435014.

[5] A. A. Blacutt, S. E. Gold, K. A. Voss, M. Gao, and A. E. Glenn, "Fusarium verticillioides: Advancements in understanding the toxicity, virulence, and niche adaptations of a model mycotoxigenic pathogen of maize," Phytopathology, vol. 108, pp. 312-326, 2018. Available at: https://doi.org/10.1094/phyto-06-17-0203-rvw.

[6] D. P. Munkvold, D. C. McGee, and W. M. Carlton, "Importance of different pathways for maize kernel infection by Fusarium monilliforme," Phytopathology, vol. 87, pp. 209-2 17, 1997.

[7] X. Gai, H. Dong, S. Wang, B. Lius, Z. Zhang, X. Li, and Z. Gao, "Infection cycle of maize stalk rot and ear rot caused by Fusarium verticillioides," PLoS one, vol. 13, p. e0201588, 2018. Available at: https://doi/org/10.1371/journal.pone.02015-88.

[8] L. Oren, S. Ezrati, D. Cohen, and A. Sharon, "Early events in the Fusarium verticillioides-maize interaction characterized by using a green fluorescent protein-expressing transgenic isolate," Applied and Environmental Microbiology, vol. 69, pp. 1695-1701, 2003. Available at: https://doi.org/10.1 128/aem.69.3.1695-1701.2003.

[9] A. Murillo-Williams and G. Munkvold, "Systemic infection by Fusarium verticillioides in maize plants grown under three temperature regimes," Plant Disease, vol. 92, pp. 1695-1700, 2008. Available at: https://doi.org/10.1094/pdis-9212-1695.

[10] W.-J. Li, H. Ping, and J.-Y. Jin, "Effect of potassium on ultrastructure of maize stalk pith and young root and their relation to stalk rot resistance," Agricultural Sciences in China, vol. 9, pp. 1467-1474, 2010. Available at: https://doi.org/10.1016/s1671-2927(09)60239-x.

[11] A. E. Desjardins and R. H. Proctor, Biochemistry and genetics of fusarium toxins. In: Fusarium. Paul, E. Nelson memorial symposium. B. Summerell, J. F Leslie, D. Backhouse, W. L. Bryden and L.W Burgesses. St.Paul, MN: American Phytopathological Society, 2001

[12] W. Gelderblom, J. Rheeder, N. Leggott, S. Stockenstrom, J. Humphreys, G. Shephard, and W. Marasas, "Fumonisin contamination of a corn sample associated with the induction of hepatocarcinogenesis in rats-role of dietary deficiencies," Food and Chemical Toxicology, vol. 42, pp. 471-479, 2004. Available at: https://doi.org/10.1016/j.fct.2003.10.010.

[13] K. A. Voss, P. C. Howard, R. T. Riley, R. P. Sharma, T. J. Bucci, and R. J. Lorentzen, "Carcinogenicity and mechanism of action of fumonisin B1: A mycotoxin produced by Fusarium moniliforme (= F. verticillioides)," Cancer Detection and Prevention, vol. 26, pp. 1-9, 2002.

[14] O. M. Olowe, A. A. Sobowale, O. J. Olawuyi, and A. C. Odebode, "Variation in pathogenicity of Fusarium verticillioides and resistance of maize genotypes to Fusarium ear rot," Archives of Phytopathology and Plant Protection, vol. 51, pp. 939950,2018

[15] C. Afolabi, P. Ojiambo, E. Ekpo, A. Menkir, and R. Bandyopadhyay, "Evaluation of maize inbred lines for resistance to Fusarium ear rot and fumonisin accumulation in grain in tropical Africa," Plant Disease, vol. 91, pp. 279-286, 2007.

[16] K. F. Alves, D. Laranjeira, M. P. Câmara, C. A. Câmara, and S. J. Michereff, "Efficacy of plant extracts for anthracnose control in bell pepper fruits under controlled conditions," Horticultura Brasileira, vol. 33, pp. 332-338, 2015. 
[17] L. Ahmad, N. Pathak, and R. Zaidi, "Antifungal potential of plant extracts against seed-borne fungi isolated from barley seeds (Hordeum vulgare L.)," Journal of Plant Pathology and Microbiology, vol. 7, pp. 1-5, 2016.

[18] D. Choudhury, P. Dobhal, S. Srivastava, S. Saha, and S. Kundu, "Role of botanical plant extracts to control plant pathogens-A review," Indian Journal of Agricultural Research, vol. 52, pp. 341-346, 2018.

[19] A. M. Ajayi and A. C. Oyedele, "Evaluation of Allium sativum (Linn) crude extract and Trichoderma asperellum (Samuel.Lieck) for antifungal properties against cowpea anthracnose pathogen," Applied Tropical Agriculture, vol. 2 1, pp. $39-45,2016$.

[20] A. B. Kutawa, M. D. Danladi, and A. Haruna, "Antifungal activity of garlic (Allium sativum) extract on some selected fungi," Journal of Medicinal Herbs and Ethnomedicine, vol. 4, pp. 12-14, 2018.

[21] A. Bianchi, A. Zambonelli, A. Z. D'Aulerio, and F. Bellesia, "Ultrastructural studies of the effects of Allium sativum on phytopathogenic fungi in vitro," Plant disease, vol. 81, pp. 1241-1246, 1997.

[22] A. J. Slusarenko and A. D. Portz, "Control of plant disease by natural product: Allicin from garlic as a case study," Nature, vol. 448, pp. 630-631, 2007.

[23] A. Perello, M. Gruhlke, and A. J. Slusarenko, "Effect of garlic on seed germination, seedling health and vigour of pathogen-infected wheat," Journal of Plant Protection Research, vol. 53, pp. 317-323, 2003.

[24] N. Deepta and M. Y. Sreenivasa, "Fusarium verticillioides, a globally important pathogen of agriculture and livestock: A review," Journal of veterinary Medicine and Research, vol. 4, pp. 1-8, 2017.

[25] A. M. Ajayi, "Bio-fungicides in Allium sativum had significant inhibition on Phytophthora megakarya (Brasier \& Griffin) and cocoa black pod rot disease," International Journal of Multidisciplinary Research and Development, vol. 6, pp. 162-169, 2019.

[26] G. J. Bollen, Lethal temperatures of soil fungi. In Ecology and management of soilborne plant pathogens. St. Paul, USA: American Phytopathological Society, 1985.

[27] F. Cheng, Z. Cheng, H. Meng, and X. Tang, "The garlic allelochemical diallyl disulfide affects tomato root growth by influencing cell division, phytohormone balance and expansin gene expression," Frontiers in Plant Science, vol. 7, p. $1199,2016$.

[28] M. Ali, S. Hayat, H. Ahmad, M. I. Ghani, B. Amin, M. J. Atif, and Z. Cheng, "Priming of Solanum melongena L. seeds enhances germination, alters antioxidant enzymes, modulates ROS, and improves early seedling growth: Indicating aqueous garlic extract as seed-priming bio-stimulant for eggplant production," Applied Sciences, vol. 9, p. $2203,2019$.

[29] S. Hayat, H. Ahmad, M. Ali, K. Hayat, M. A. Khan, and Z. Cheng, "Aqueous garlic extract as a plant biostimulant enhances physiology, improves crop quality and metabolite abundance, and primes the defense responses of receiver plants," Applied Sciences, vol. 8, p. 1505, 2018.

[30] R. N. Strange and P. Scot, "Plant disease: A threat to global food security," Annual Review of Phytopathology, vol. 43, pp. 83-116, 2005.

Online Science Publishing is not responsible or answerable for any loss, damage or liability, etc. caused in relation to/arising out of the use of the content. Any queries should be directed to the corresponding author of the article. 